\title{
PENGARUH MASA KERJA, SPESIALISASI AUDIT, DAN KOMITE AUDIT TERHADAP KUALITAS AUDIT \\ (Studi Kasus Pada Perbankan Syariah Di Indonesia)
}

\author{
Rizka Fitriani ${ }^{1}$ \\ 1Politeknik Negeri Semarang \\ $\triangle$ rizkaftrn7@gmail.com
}

\begin{abstract}
The rise of fictitious financing carried out by unscruplous bank employees makes people doubt the truth of the contents of financial statements issued by banks. This can be bad for Islamic Banks in Indonesia that are developing rapidly. To prevent this from happening again and again, Islamic Banks can conduct periodic audits to anticipate fraud at Islamic Banks.

This research aims to determine the effect of tenure, audit specialization and audit committee on audit quality both simultaneously and partially. The population in this research is all Islamic Banking in Indonesia amounting to 14 banks. While the sampling technique used was purposive sampling in the category of Islamic Banking which issued financial statements from 2014 2018 which produced 13 samples of Islamic Banks. This study uses multiple linier regression analysis method using IBM SPSS Statistics 24. From this research it can be concluded that simultaneously the variables of tenure, audit specialization and audit committee have a significant effect on audit quality. But only affect around 29,5\%. partially, only audit committee has a significant effect on audit quality. While audit soecialization is removed as an indicator of audit quality because it is considered constant.
\end{abstract}

Keywords $\quad$ : Tenure, Audit Specialization, Audit Committees, dan Audit Quality.

\section{LATAR BELAKANG}

Banyaknya kasus kecurangan (fraud) yang dilakukan oleh oknum karyawan Bank Syariah, membuat publik bertanya-tanya tentang kebenaran isi laporan keuangan Bank Syariah. Kasus pembiayaan fiktif dengan besaran yang tidak sangat besar, membuat masyarakat bertanya bagaimana bisa hal itu dapat terjadi. Setelah semua berita tersebut, banyak yang meragukan keaslian dari laporan keuangan yang diterbitkan. Apakah benar laporan tersebut sesuai dengan keadaan sebenarnya atau hanya angka yang tidak dapat dipertanggung jawabkan asal usulnya.

Dengan perkembangan Bank Syariah yang sudah sangat pesat, sangat disayangkan jika harus ternodai dengan kasus-kasus pembiayaan fiktif yang dapat membuat masyarakat enggan menggunakan bank syariah karena ragu jika nantinya uangnya akan digunakan untuk hal-hal yang tidak dapat dipertanggungjawabkan. Untuk mencegah kejadian-kejadian tersebut, bank syariah dapat melakukan tindakan pencegahan dengan melakukan audit secara intensif.

Kualitas audit dinilai sangat penting terutama bagi pemegang saham. Dengan baiknya kualitas audit yang dimiliki sebuah perusahaan akan membuat pemegang saham menjadi tidak khawatir investasinya akan hilang karena dapat dipertanggung 
jawabkan dan bila terjadi kecurangan (fraud) dapat dideteksi dini dan dilakukan pencegahan. Ada beberapa hal yang dapat mempengaruhi kualitas audit sebuah perusahaan diantaranya, masa kerja (tenure), spesialisasi audit, dan komite audit.

Menurut penelitian yang dilakukan oleh Panjaitan \& Chairiri (2014), menyatakan bahwa masa kerja (tenure) berpengaruh signifikan terhadap kualitas audit. Sama halnya dengan penelitian yang dilakukan oleh Nadia (2015) yang mengungkapkan bahwa masa kerja (tenure) berpengaruh signifikan terhadap kualitas audit. Hal yang membedakan kedua penelitian ini adalah arah pengaruhnya. Penelitian yang dilakukan Panjaitan \& Chairiri (2014), mengatakan bahwa masa kerja (tenure) berpengaruh negatif. Hal ini sama dengan penelitian Prasetia dan Rozali (2016) yang mengungkapkan bahwa masa kerja memiliki pengaruh yang negatif terhadap kualitas audit. Sedangkan penelitian yang dilakukan oleh Nadia (2015) menyatakan bahwa masa kerja memiliki pengaruh yang positif terhadap kualitas audit.

Penelitian tentang spesialisasi audit yang dilakukan oleh Nizar (2017) mengungkapkan bahwa spesialisasi auditor tidak berpengaruh signifikan terhadap kualitas audit. Hasil tersebut sama dengan penelitian yang dilakukan oleh Pramaswaradana dan Astika (2017) yang menyebutkan bahwa spesialisasi audit tidak memberikan penagruh yang signifikan terhadap kualitas audit.

\section{TEORI DAN METODE}

\subsection{Tenur Audit}

Tenur audit adalah masa perikatan (jangka waktu) antara auditor dengan klien terkait jasa audit yang disepakati. Tenure menjadi perdebatan pada saat tenure audit yang dilakukan terlalu singkat dan tenure audit yang dilakukan dalam jangka waktu lama (Fierdha et al 2014). Tenure sendiri dapat berdampak pada kinerja auditor pada perusahaan klien seperti hubungan emosional auditor dengan klien, independensi, fee audit, profesionalisme kerja, kompetensi, dsb.

\subsection{Spesialisasi Audit}

Spesialisasi adalah suatu kemampuan yang dimiliki oleh seseorang dalam bidang tertentu sehingga membuat orang tersebut mampu mengerjakan sesuatu dengan lebih cermat dan teliti dibandingkan orang yang tidak memiliki spesialisasi (Ishak et al, 2014). Variabel spesialisasi ini mengacu pada Ishak et al. (2015) di proksikan dengan mengunakan auditor industry specialization. Dikatakan bahwa partner audit dikatakan spesialis apabila mengaudit 15 persen dari total perusahaan yang ada dalam industry tersebut. Presentase auditor industry specialization (AIS) dihitung sebagai berikut:

Jumlah klien KAP dalam industri

$$
\begin{aligned}
& \text { AIS = - --- - ----: ---- - --- - ---- }-\mathrm{x} 100 \% \\
& \text { Jumlah emiten dalam industri }
\end{aligned}
$$

Nilai auditor spesialisasi dihitung dengan menggunakan dummy variabel, angka 1 akan diberi untuk auditor spesialis dan angka 0 untuk auditor yang tidak spesialis. 


\subsection{Komite Audit}

Komite audit adalah suatu badan yang dibentuk didalam perusahaan klien yang bertugas untuk memelihara independensi akuntan pemeriksa terhadap manajemen (Supriyono, dalam Hardiningsih 2010). Komite audit diukur secara numeral dari jumlah anggota komite audit yang terdapat pada perusahaan dalam annual report (Agustin dalam Ulina et. al, 2018).

\subsection{Kualitas Audit}

Audit adalah akumulasi dan evaluasi bukti tentang informasi untuk menentukan dan melaporkan tingkat kesesuaian antara informasi dan kriteria yang telah ditetapkan. Menurut Rosnidah dalam Andriani dan Nursiam (2017) kualitas audit adalah pelaksanaan audit yang dilakukan sesuai dengan standar sehingga mampu mengungkapkan dan melaporkan apabila terjadi pelanggaran yang dilakukan klien. Audit memiliki fungsi sebagai proses untuk mengurangi ketidakselarasan informasi yang terdapat antara manajer dan para pemegang saham dengan menggunakan pihak luar untuk memberikan pengesahan terhadap laporan keuangan.

DeAngelo (1981) menyatakan bahwa kualitas audit dari akuntan publik dapat dilihat dari ukuran KAP yang melakukan audit. KAP besar (Big 4 accounting firms) diyakini melakukan audit lebih berkualitas dibandingkan dengan KAP kecil (Non-Big 4 accounting firms). Ukuran KAP yang besar menjelaskan kemampuan auditor untuk bersikap independen dan profesional.

\subsection{Metode Penelitian}

Metode yang digunakan dalam penelitian ini adalah metode analisis regresi linier berganda dengan menggunakan IBM SPSS Statistik 24. Populasi dalam penelitian ini adalah seluruh perbankan syariah di Indonesia yang berjumlah 14 bank. Teknik sampling yang digunakan adalah purposive sampling dengan kategori bank syariah yang menerbitkan laporan keuangan periode 2014 - 2018 dan terdapat laporan audit. Menghasilkan 13 bank yang lolos dalam kategori ini.

\subsection{Kerangka Pemikiran Teoritis \& Hipotesis}

Berikut ini adalah kerangka pemikiran teoritis dari penelitian ini yang dapat dilihat pada Gambar 2.1. 
Gambar 2.1.

Kerangka Pemikiran Teoritis

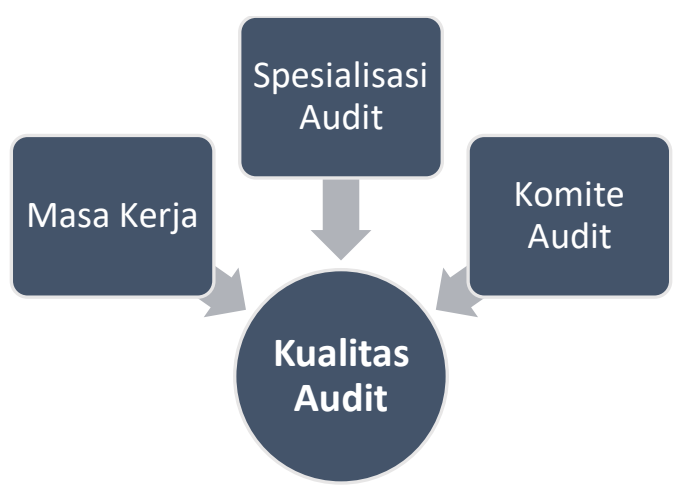

Gambar 2.1. Kerangka Pemikiran Teoritis

H1 : Masa Kerja, Spesialisasi Audit dan Komite Audit secara simultan berpengaruh signifikan terhadap Kualitas Audit

H2 : Masa Kerja secara parsial berpengaruh signifikan terhadap Kualitas Audit

H3 : Spesialisasi Audit secara parsial berpengaruh signifikan terhadap Kualitas Audit

H4 : Komite Audit secara parsial berpengaruh signifikan terhadap Kualitas Audit

\section{HASIL DAN PEMBAHASAN}

\subsection{Hasil Analisis Data}

Uji hipotesis digunakan untuk menguji hipotesis penelitian yang telah dirumuskan sebelumnya, yaitu untuk mengetahui pengaruh variabel Masa Kerja, Spesialisasi Audit dan Komite Audit terhadap Kualitas Audit pada Bank Syariah.

\section{Uji Signifikansi Simultan}

Uji Signifikansi Simultan (Uji F) digunakan untuk melihat apakah variabel independen dapat menjelaskan variabel dependen secara keseluruhan. Hasil dari pengujian signifikansi dapat dilihat pada Tabel 3.1.

Tabel 3.1.

Model Summary

\begin{tabular}{|c|c|c|c|c|c|c|}
\hline \multicolumn{7}{|c|}{ ANOVA $^{a}$} \\
\hline Model & & Sum of Squares & $\mathrm{df}$ & Mean Square & $\mathrm{F}$ & Sig. \\
\hline \multirow[t]{3}{*}{1} & Regression & 5,137 & 2 & 2,568 & 14,373 &, $000^{\mathrm{b}}$ \\
\hline & Residual & 11,079 & 62 & , 179 & & \\
\hline & Total & 16,215 & 64 & & & \\
\hline
\end{tabular}

Sumber : Data yang diolah, 2020

Berdasarkan hasil pengujian signifikansi simultan (Uji F) menunjukkan nilai F $=14,373$ dengan probabilitas sebesar $0,00<0,05$. Hal ini berarti seluruh variabel independen jika diuji bersamaan dalam waktu yang sama mempunyai pengaruh yang 
signifikan terhadap variabel dependen. Hasil ini juga menunjukkan bahwa model termasuk fit model.

\section{Uji Koefisien Determinasi}

Uji koefisien determinasi (Adjusted $R$ Square) digunakan untuk mengetahui seberapa besar kontribusi pengaruh variabel - variabel independen (Masa Kerja, Spesialisasi Audit, dan Komite Audit) terhadap variabel dependen (Kualitas Audit). Hasil dari pengujian koefisien determinasi dapat dilihat pada Tabel 3.2.

Tabel 3.2.

Uji Koefisien Determinasi

\begin{tabular}{|c|c|c|c|c|}
\hline \multicolumn{5}{|c|}{ Model Summary } \\
\hline Model & $\mathrm{R}$ & R Square & $\begin{array}{l}\text { Adjusted R } \\
\text { Square }\end{array}$ & $\begin{array}{c}\text { Std. Error of the } \\
\text { Estimate }\end{array}$ \\
\hline 1 &, $563^{a}$ & 317 & ,295 & ,423 \\
\hline
\end{tabular}

Nilai adjusted $R$ square $\left(\mathrm{R}^{2}\right)$ diperoleh sebesar 0,295. Hasil ini menunjukkan bahwa 29,5\% kualitas audit dapat dijelaskan oleh variabel masa kerja, spesialisasi auditor dan komite audit sedangkan sisanya 71,5\% kualitas audit dapat dijelaskan oleh variabel-variabel lain.

Uji Hipotesis

Uji hipotesis digunakan untuk mengetahui signifikansi variabel - variabel independen (Masa Kerja, Spesialisasi Audit, dan Komite Audit) secara individual terhadap variabel deoenden (Kualitas Audit). Uji hipotesis dilakukan dengan menggunakan uji t dengan hasil yang dapat dilihat pada Tabel 3.3.

Tabel 3.3.

Uji t

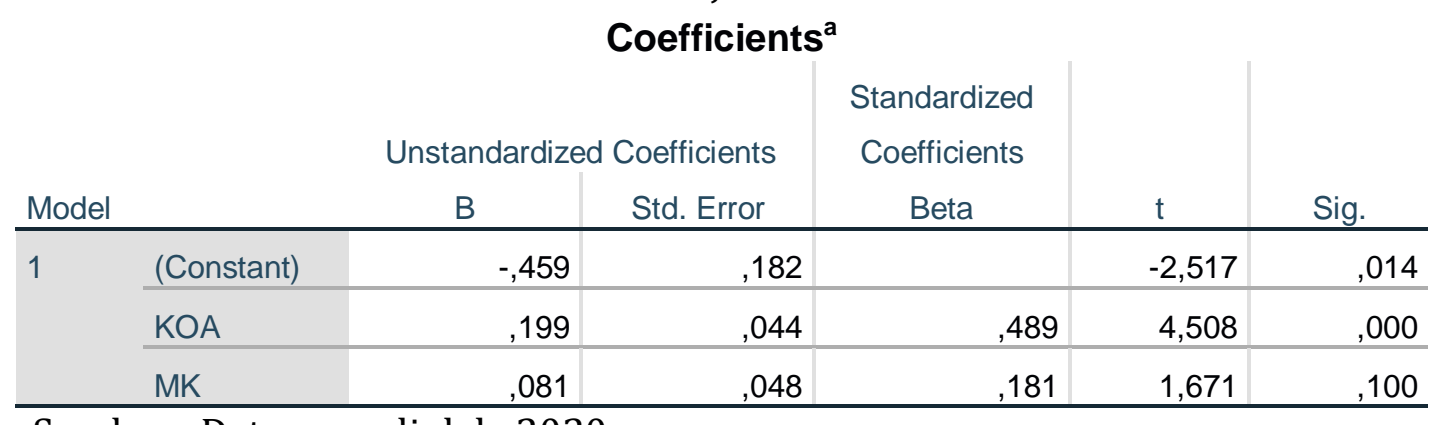

Sumber : Data yang diolah, 2020

Pengaruh tiap variabel independen terhadap variabel dependen dapat dijelaskan sebagai berikut.

a) Pengaruh Komite Audit terhadap Kualitas Audit

Hasil pengujian pengaruh Komite Audit terhadap Kualitas Audit menunjukkan nilai thitung sebesar 4,508 dengan nilai tingkat signifikansi sebesar 0,000. Hasil ini menunjukkan bahwa Komite Audit berpengaruh signifikan terhadap Kualitas Audit. Nilai koefisien regresi Komite Audit sebesar 0,489 menunjukkan bahwa pada saat variabel Komite Audit meningkat 1 (satu) satuan maka variabel Kualitas Audit akan naik sebesar 0,489 dengan asumsi variabel lain dianggap tetap. Hasil 
ini juga mengindikasian bahwa Komite Audit berpengaruh signifikan terhadap Kualitas Audit.

b) Pengaruh Masa Kerja terhadap Kualitas Audit

Hasil pengujian pengaruh Masa Kerja terhadap Kualitas Audit menunjukkan nilai $t_{\text {hitung }}$ sebesar 1,671 dengan nilai tingkat signifikansi sebesar 0,100. Hasil ini menunjukkan bahwa Masa Kerja tidak berpengaruh signifikan terhadap Kualitas Audit. Dari sisi arah pengaruh, arah hubungan yang keduanya sesuai dengan hipotesis yang diajukan dalam penelitian ini. Nilai koefisien regresi Masa Kerja sebesar 0,181 menunjukkan bahwa pada saat variabel Masa Kerja meningkat 1 (satu) satuan maka variabel volume pembiayaan akan naik sebesar 0,181 dengan asumsi variabel lain dianggap tetap. Hasil ini juga mengindikasian bahwa Masa Kerja tidak berpengaruh signifikan terhadap Kualitas Audit.

c) Pengaruh Spesialisasi Audit terhadap Kualitas Audit

Tidak terdapat hasil yang dapat ditunjukkan pada uji ini karena variabel Spesialisasi Audit dihapuskan karena dianggap konstan/tetap. Maksudnya, seluruh bank syariah di Indonesia, memiliki spesialisasi auditor yang sama.

\section{PENUTUP}

Hasil penelitian ini menunjukkan bahwa secara simultan, Masa Kerja, Spesialisasi Audit dan Komite Audit berpengaruh signifikan terhadap Kualitas Audit di Bank Syariah di Indoneia. Namun, hanya memberikan dampak sebesar 29,5\%. Sedangkan secara parsial, hanya variabel Komite Audit yang berpengaruh signifikan terhadap Kualitas Audit. Variabel Masa Kerja tidak berpengaruh signifikan terhadap Kualitas Audit, dan variabel Spesialisasi Audit harus dihapuskan karena dianggap konstan/tetap (semua bank syariah pada periode 2014 - 2018 memiliki nilai yang sama untuk kategori spesialisasi audit).

Saran untuk peneliti selanjutnya agar mengganti metode analisis atau mengganti variabel lain yang sekiranya berpotensi memiliki pengaruh terhadap Kualitas Audit. Saran lain yang dapat dilakukan adalah menambah variabel independen. Atau dapat juga dilakukan penggantian tolok ukur agar mendapat hasil yang sesuai dengan yang diinginkan. 


\section{DAFTAR PUSTAKA}

Atmojo, R. T., \& Sukirman (2019). Effect of Tenure, Audit Specialization, and KAP's Reputation on the Quality of Audit Mediated by Audit Committees. Accounting Analysis Journal 8(1) (2019) 66-73.

Prasetia, I. F., \& Rozali, R. D. Y. (2016). Pengaruh Tenur Audit, Rotasi Audit Dan Reputasi Kap Terhadap Kualitas Audit (Studi Pada Perusahaan Manufaktur Yang Terdaftar Di Bursa Efek Indonesia Tahun 2011-2014). Jurnal Aset (Akuntansi Riset) 8(1), (2016) 39-50.

Ishak, Febrian Adhi, Halim Dedy dan Anis Widjajanto. 2015. Pengaruh Rotasi Audit, Workload dan Spesialisasi Terhadap Kualitas Audit pada Perusahaan Manufaktur yang Terdaftar di BEI pada Tahun 2009-2013. Jurnal Organisasi dan Manajemen, Vol.11, No.2.

Fierdha, H. Gunawan dan P. Purnamasari. 2014. Pengaruh Audit Rotation dan Audit Tenure Terhadap Kualitas Audit dengan Fee Audit sebagai Varibel Pemoderasi. Prosiding Ilmu Ekonomi Universitas Islam Bandung.

Andriani, N. \& Nursiam (2017). Pengaruh Fee Audit, Audit Tenure, Rotasi Audit Dan Reputasi Auditor Terhadap Kualitas Audit (Studi Empiris Pada Perusahaan Manufaktur yang Terdaftar di Bursa Efek Indonesia Tahun 2013-2015). Riset Akuntansi dan Keuangan Indonesia 3(1) 2018.

Hardiningsih, P. (2010). Pengaruh Independensi, Coporate Governance, dan Kualitas Audit terhadap Integritas Laporan Keuangan. Kajian Akuntansi. Volume 2. Nomor (1).

Ulina, R., Mulyadi, R., \& Tjahjono, M. E. S. (2018). Pengaruh Kualitas Audit Dan Komite Audit Terhadap Manajemen Laba Pada Perusahaan Manufaktur Yang Tercatat Di Bursa Efek Indonesia. Tirtayasa Ekonomika Vol. 13, No 1, April 2018.

DeAngelo, L.E. (1981). Auditor size and audit quality. Journal of Accounting and Economics, 3, (3), 183-199.

Panjaitan, C. M., \& Chariri, A. (2014). Pengaruh Tenure, Ukuran KAP Dan Spesialisasi Auditor terhadap Kualitas Audit. Diponegoro Journal Of Accounting Volume 3, Nomor 3, Tahun 2014, Halaman 1-12 ISSN (Online): 2337-3806.

Nadia, N. F. (2015). Pengaruh Tenur KAP, Reputasi Kap Dan Rotasi Kap Terhadap Kualitas Audit. Jurnal Akuntansi Bisnis, Vol. XIII No. 26 Maret 2015.

Nizar, A. A. (2017). Pengaruh Rotasi, Reputasi dan Spesialisasi Auditor Terhadap Kualitas Audit (Studi Empiris pada Perusahaan Manufaktur Listed di BEI). Jurnal Ilmiah Akuntansi: Kompartemen Vol. XV No.2, September 2017.

Pramaswaradana, I G. N. I., \& Astika I. B. P. (2017). Pengaruh Audit Tenure, Audit Fee, Rotasi Auditor, Spesialsiasi Auditor, Dan Umur Publikasi Pada Kualitas Audit. E-Jurnal Akuntansi Universitas Udayana Vol.19.1. April (2017): 168-194 Issn: 2302-8556. 
Halaman ini sengaja dikosongkan 